\title{
Alcohol consumption, cigarette smoking, and familial breast cancer risk: findings from the Prospective Family Study Cohort (ProF-SC)
}

Nur Zeinomar ${ }^{1}$, Julia A. Knight ${ }^{2,3}$, Jeanine M. Genkinger ${ }^{1,4}$, Kelly-Anne Phillips ${ }^{5,6,7}$, Mary B. Daly ${ }^{8}$, Roger L. Milne $e^{5,9,10,}$ Gillian S. Dite ${ }^{5}$, Rebecca D. Kehm¹, Yuyan Liao', Melissa C. Southey 9,10,11, Wendy K. Chung ${ }^{4,12}$, Graham G. Giles 5,9,10, Sue-Anne McLachlan ${ }^{13,14}$, Michael L. Friedlander ${ }^{15,16}$, Prue C. Weideman ${ }^{5}$, Gord Glendon², Stephanie Nesci, kConFab Investigators ${ }^{7,17}$, Irene L. Andrulis ${ }^{2,18}$, Saundra S. Buys ${ }^{19}$, Esther M. John ${ }^{20}$, Robert J. MacInnis ${ }^{5,9}$, John L. Hopper ${ }^{5}$ and Mary Beth Terry ${ }^{1,4^{*}}$ (D)

\begin{abstract}
Background: Alcohol consumption and cigarette smoking are associated with an increased risk of breast cancer (BC), but it is unclear whether these associations vary by a woman's familial BC risk.

Methods: Using the Prospective Family Study Cohort, we evaluated associations between alcohol consumption, cigarette smoking, and BC risk. We used multivariable Cox proportional hazard models to estimate hazard ratios $(\mathrm{HR})$ and $95 \%$ confidence intervals $(\mathrm{Cl})$. We examined whether associations were modified by familial risk profile (FRP), defined as the 1-year incidence of BC predicted by Breast Ovarian Analysis of Disease Incidence and Carrier Estimation Algorithm (BOADICEA), a pedigree-based algorithm.
\end{abstract}

Results: We observed 1009 incident BC cases in 17,435 women during a median follow-up of 10.4 years. We found no overall association of smoking or alcohol consumption with BC risk (current smokers compared with never smokers HR 1.02, 95\% Cl 0.85-1.23; consuming $\geq 7$ drinks/week compared with non-regular drinkers HR 1.10,95\% Cl 0.92-1.32), but we did observe differences in associations based on FRP and by estrogen receptor (ER) status. Women with lower FRP had an increased risk of ER-positive BC associated with consuming $\geq 7$ drinks/week (compared to non-regular drinkers), whereas there was no association for women with higher FRP. For example, women at the 10th percentile of FRP (5year BOADICEA $=0.15 \%)$ had an estimated HR of $1.46(95 \% \mathrm{Cl} 1.07-1.99)$, whereas there was no association for women at the 90th percentile (5-year BOADICEA $=4.2 \%)(\mathrm{HR} 1.07,95 \% \mathrm{Cl} 0.80-1.44)$. While the associations with smoking were not modified by FRP, we observed a positive multiplicative interaction by FRP ( $\left.p_{\text {interaction }}=0.01\right)$ for smoking status in women who also consumed alcohol, but not in women who were non-regular drinkers.

Conclusions: Moderate alcohol intake was associated with increased BC risk, particularly for women with ER-positive $B C$, but only for those at lower predicted familial BC risk (5-year BOADICEA < 1.25). For women with a high FRP (5-year BOADICEA $\geq 6.5 \%$ ) who also consumed alcohol, being a current smoker was associated with increased BC risk.

Keywords: Breast cancer, Alcohol consumption, Cigarette smoking, Familial risk, BOADICEA

\footnotetext{
* Correspondence: mt146@cumc.columbia.edu

'Department of Epidemiology, Mailman School of Public Health, Columbia

University, 722 W. 168th Street, Room 1611, New York, NY 10032, USA

${ }^{4}$ Herbert Irving Comprehensive Cancer Center, Columbia University Irving

Medical Center, New York, NY, USA

Full list of author information is available at the end of the article
}

(c) The Author(s). 2019 Open Access This article is distributed under the terms of the Creative Commons Attribution 4.0 International License (http://creativecommons.org/licenses/by/4.0/), which permits unrestricted use, distribution, and

reproduction in any medium, provided you give appropriate credit to the original author(s) and the source, provide a link to the Creative Commons license, and indicate if changes were made. The Creative Commons Public Domain Dedication waiver (http://creativecommons.org/publicdomain/zero/1.0/) applies to the data made available in this article, unless otherwise stated. 


\section{Background}

Alcohol consumption is an established breast cancer (BC) risk factor, with a $7-10 \%$ increase in $\mathrm{BC}$ risk for each standard alcoholic drink consumed daily (12 fl oz. of beer, $5 \mathrm{fl} \mathrm{oz}$. of wine, or $1.5 \mathrm{fl} \mathrm{oz}$. of hard liquor) [1-6]. The association between cigarette smoking and $\mathrm{BC}$ risk has been less consistently observed, but the current weight of evidence points to a modest association [7-9]. A recent meta-analysis of 49 epidemiologic studies reported an $11 \%$ increase in $\mathrm{BC}$ risk for current smokers (RR 1.11, 95\% CI 1.06-1.16), compared with never smokers [9]. Since alcohol is an established and modest risk factor for $\mathrm{BC}$, concerns of residual confounding by alcohol consumption when examining the association of smoking with $\mathrm{BC}$ risk have been raised [2]. Some evidence points more to synergy between the two risk factors. For example, in a pooled analysis of 14 cohorts that stratified by amount of alcohol intake, the elevated BC risk associated with being a current smoker compared with non-current smokers was only observed for women who consumed alcohol [8].

The majority of epidemiological evidence has been collected from women at general population risk and has included few high-risk women; few studies have examined these modifiable factors for women across the spectrum of absolute $\mathrm{BC}$ risk. In the limited number of prospective studies with adequate sample size, no clear association between alcohol consumption and $\mathrm{BC}$ risk has been observed in BRCA1 or BRCA2 mutation carriers (for review see [10]). A recent prospective study of mutation carriers reported weak evidence of increased $\mathrm{BC}$ risk for current smokers compared with never smokers (HR 1.28; 95\% CI 1.00-1.64) [11].

Estimates of relative risks from cohorts with large variation in absolute $\mathrm{BC}$ risk are important to understand associations with modifiable factors on an absolute risk scale [12]. For example, we have found that several risk factors for BC do not vary by FRP (tested as multiplicative interactions) including benign breast disease and high body mass index (BMI), which is important to highlight because it means that on an absolute level, women at higher $\mathrm{BC}$ risk may benefit more from the relative risk reductions [13-16]. Of the few studies that have examined interaction between $\mathrm{BC}$ family history and either alcohol consumption or cigarette smoking, three have suggested similar associations regardless of family history [17-19], while others found a lack of associations with smoking or alcohol for women with primarily a first-degree BC family history [4, 20-22]. These studies, however, were limited in evaluating interaction with $\mathrm{BC}$ family history, as only a small proportion (4-13\%) of participants had a family history [18, 19, 21]. Additionally, most studies only examined family history as a binary construct (yes/no) and did not examine modification of risk across the spectrum of absolute $\mathrm{BC}$ risk. Thus, evidence from prospective cohorts with sufficient statistical power to examine the association of modifiable exposures across the spectrum is essential and an important first step in developing appropriate clinical recommendations for women across the risk spectrum, and particularly for women at the higher end of the risk spectrum who may only be given clinical advice on modifiable factors based on average risk women and/or not advised at all. We examined whether cigarette smoking and alcohol consumption were associated with BC risk in women across the spectrum of absolute familial risk, using a prospective cohort enriched for women at familial or genetic risk.

\section{Methods}

\section{Study population}

The Prospective Family Study Cohort (ProF-SC) [12] includes women enrolled in the Breast Cancer Family Registry (BCFR) which includes six breast cancer family studies in the USA, Canada, and Australia [23], and the Kathleen Cuningham Foundation Consortium for research into Familial Breast cancer (kConFab) Follow-up Project $[24,25]$. All probands and their family members were followed prospectively from baseline for cancer and other health outcomes [12]. Screening for germline $B R C A 1$ and BRCA2 mutations was conducted, as previously described [23, 26, 27]. The institutional review board at each participating study center approved the BCFR and kConFab, and all participants provided written informed consent.

In the current analysis, we studied women unaffected with breast cancer, aged 18 to 79 years at recruitment (baseline), who had at least 2 months of follow-up, and did not to have a bilateral risk-reducing mastectomy at baseline $(N=17,780)$. We excluded 191 women without sufficient pedigree data to allow calculation of a lifetime $\mathrm{BC}$ risk score using the Breast Ovarian Analysis of Disease Incidence and Carrier Estimation Algorithm (BOADICEA), and 236 women for whom we did not have complete data on alcohol consumption (whether they were regular or non-regular drinkers, as defined below) and cigarette smoking (whether they were current, former, or never smokers). From the 17,780 unaffected women in the original cohort, this left 17,435 (98.1\%) available for analysis.

\section{Questionnaires}

The BCFR and kConFab used the same core questionnaires at baseline [12]. The questionnaires asked about the participants' demographic characteristics; education; race/ethnicity; height and weight; menstrual and reproductive history, including age at menarche, parity, breastfeeding, age at first birth, and age at menopause; hormonal birth control; menopausal hormone therapy 
use; medical history including diagnosis of breast or ovarian cancer, and breast or ovarian surgeries; and behavioral factors including cigarette smoking and alcohol consumption. Probands also completed a family history questionnaire that asked about breast and other cancers in their first-degree and second-degree relatives. Each participant's cancer information was obtained from one or more sources and was usually self-reported or reported by a first-degree relative. We confirmed reported invasive $\mathrm{BC}$ diagnosis through pathology reports or cancer registry linkages for $81 \%$ of incident cases.

Definitions of cigarette smoking and alcohol consumption Baseline questionnaires included a detailed assessment of lifetime cigarette smoking and alcohol consumption, including questions about current and former smoking and drinking, duration of smoking and drinking, age at smoking and drinking initiation, average numbers of cigarettes smoked per day, and average number of each type of alcoholic drink (beer, wine/wine cooler, and liquor) consumed per week.

We classified women as ever smokers if they answered "yes" and as never smokers if they answered "no" to the following question: "Have you smoked at least one cigarette per day for 3 months or longer?". For ever smokers, we defined additional exposure variables, including smoking status (former or current), age at smoking initiation $(<16,16$ to $<18,18$ to $<20$, or $\geq 20$ years), smoking duration $(<10,10$ to $<20,20$ to $<30$, or $\geq 30$ years), and smoking intensity ( 1 to $<5,5$ to $<10,10$ to $<20$, or $\geq 20$ cigarettes per day). We classified women as regular drinkers if they answered "yes" and as nonregular drinkers if they answered "no" to the following question: "Have you ever consumed any alcoholic beverages, such as beer, wine, or liquor, at least once a week for 6 months or longer?". For regular drinkers, we defined additional exposure variables, including age at drinking initiation $(<18,18$ to $<21,21$ to $<30$, or $\geq 30$ years) and number of alcoholic drinks consumed per week $(<7$ or $\geq 7)$, a common cut point in the literature. We defined one drink as a $12 \mathrm{oz}$. serving of beer, one medium glass of wine or wine cooler, or one shot of liquor, and calculated alcoholic drinks per week as the sum of the intake of each of the three different types of alcoholic beverages consumed.

\section{Familial risk profile}

For each participant, we calculated a 1-year, 10-year, and lifetime (from birth to age 80 years) risk of invasive $\mathrm{BC}$ from multigenerational pedigree data on breast and ovarian cancer in relatives using the BOADICEA version $3[28,29]$. This algorithm uses information on ovarian and female and male breast cancer and age at diagnosis for first-, second-, and third-degree relatives (where available), along with date of birth, vital status, age at interview or death, and country- and age-specific breast cancer incidence to calculate risk. Where available, information on BRCA1 and BRCA2 mutation testing was also used to calculate risk. We hereafter refer to this continuous risk score as the familial risk profile (FRP). A previous validation study of family cancer history information communicated within families in the BCFR found high sensitivity and specificity for family history of breast cancer [30]. Additionally, a recent validation study of commonly used breast cancer risk prediction models in ProF-SC found BOADICEA to be well calibrated (ratio of expected cases to observed cases 1.05 (95\% CI 0.97-1.14); C-statistic 0.70 (95\% CI 0.68-0.72)) [31].

\section{Statistical methods}

We used Cox proportional hazard regression models with age as the time scale to estimate hazard ratios (HR) and their 95\% confidence intervals (CI) for BC associated with FRP and each smoking and alcohol variable. We calculated person-years from 2 months after the age at completion of the baseline questionnaire to the age at diagnosis of $\mathrm{BC}$ or the earliest of the following events: age at risk-reducing mastectomy, age at death, age 80 years, or age last known to be alive. We used a robust variance estimator to account for the family structure of the cohort. We incorporated left-truncation in all models to avoid potential survivor bias. All models were stratified by birth cohort (<1950, 1950-1959, 1960$1969, \geq 1970$ ) and adjusted for race/ethnicity (non-Hispanic white; non-Hispanic black; Hispanic; Asian; other) and study center. We considered the following variables measured at baseline as potential confounders: age at baseline (continuous), body mass index (BMI, continuous), education ( $\leq$ high school or general education development; vocational, technical, some college, or some university; bachelor or graduate degree), age at menarche (continuous), parity and breastfeeding (nulliparous; 1-2 full-term pregnancies and did not breast feed; $1-2$ full-term pregnancies and breastfed; $\geq 3$ full-term pregnancies and did not breast feed; $\geq 3$ full-term pregnancies and breastfed), age at first birth (continuous and centered at mean), oral contraceptive use (current, former, never user), menopausal hormone use (current, former, never user), and menopausal status (pre- or post-menopausal). We also assessed for confounding by alcohol consumption (regular or non-regular drinker) in the smoking models and confounding by cigarette smoking (current, former, and never smoker) in the alcohol models. We included as confounding variables in the final models any variable that changed the smoking or drinking parameter estimate of interest by more than $10 \%$. We assessed multiplicative interaction with FRP using the 1-year BOADICEA risk score and each 
smoking and alcohol variable of interest by including a cross-product term in the model and assessing the corresponding beta coefficient using the Wald test. We also estimated associations by estrogen receptor (ER) status (positive or negative), where the alternative ER subtype was censored at diagnosis. For example, ER-positive cases were censored at diagnosis in models examining ER-negative breast cancer. For ease of interpretation, we also present HRs by high and low FRP, using $0.34 \%$ as a categorical cutoff for absolute 1-year risk because it is the 1 -year equivalent to the 5 -year risk cutoff of $1.67 \%$. We performed the following sensitivity analyses: including only those with confirmed invasive $\mathrm{BC}$ based on pathology reports or cancer registry linkages $(81 \%$ of all cases were confirmed invasive), where unconfirmed cancers were censored at diagnosis, excluding those with a prior diagnosis of any cancer (except non-melanoma skin cancer) at baseline, and excluding BRCA1 and $B R C A 2$ mutation carriers. We assessed the proportional hazards assumption by evaluating the Schoenfeld residuals. All statistical tests were two sided, and $p$ values < 0.05 were considered statistically significant. All statistical analyses were performed using SAS software version 9.4 (SAS Institute Inc., Cary, NC, USA).

\section{Results}

We followed 17,435 women from 6948 families in the BCFR and kConFab with an average age at enrollment into the cohorts of 46.7 years. During the 181,062 person-years of follow-up (median 10.4, maximum 24.0 years), there were 1009 incident cases of BC with an average age at diagnosis of 56.2 years. Of the 17,435 women, 15\% $(n=2602)$ reported currently smoking at baseline, 27\% $(n=4675)$ reported formerly smoking, and $58 \%(n=10,158)$ reported being never smokers. Current smokers smoked more intensely (mean cigarettes/day 15.1 vs 13.1) and for a longer period (mean duration 23.9 vs 14.5 years) than former smokers (Table 1$)$. Overall, $49 \%(n=8618)$ of women reported being regular drinkers of alcoholic beverages at baseline and reported consuming an average of 7.7 total alcoholic drinks/week. Compared with never smokers, current and former smokers were more likely to be regular drinkers $(63 \%$ and $66 \%$, respectively, vs $38 \%$ for never smokers) and consumed more alcoholic drinks per week (mean drinks per week 10.9 and 8.0, respectively, compared with 6.0 for never smokers).

Overall, there was no statistically significant association between smoking status and BC risk (former smokers HR 1.06, 95\% CI 0.92-1.22; current smokers HR 1.02, 95\% CI 0.85-1.23, compared with never smokers). We also observed no statistically significant associations between smoking status and risk of ERpositive BC (former smokers HR 0.97, 95\% CI 0.77-1.21; current smokers HR 1.04, 95\% CI 0.77-1.4, compared with never smokers) or risk of ER-negative BC (former smokers HR 0.95, 95\% CI 0.63-1.41; current smokers HR 1.22, 95\% CI 0.78-1.91, compared with never smokers) (Table 2). Figure 1 illustrates the association of being a current smoker (as compared to never smoking) by percentiles of absolute predicted 1-year BC risk. Although the overall interaction term was statistically significant ( $p$ value 0.03), the individual HRs at different percentiles of FRP were not, with HRs of 1.04 (95\% CI $0.86-1.25)$ and 0.92 (95\% CI $0.74-1.15)$ for women in the 90th and 10th percentile of 1-year BOADICEA risk score, respectively (Fig. 1). These results were consistent for other measures of FRP we examined, including 10year BOADICEA risk score and lifetime risk to age 80 (results not shown).

Overall, there was no statistically significant association between alcohol consumption and overall BC (relative to non-regular drinkers, HR for $<7$ drinks per week $0.99,95 \%$ CI $0.85-1.16$; HR for $\geq 7$ drinks per week 1.10, 95\% 0.92-1.32) (Table 3). We also observed no significant associations between alcohol consumption and risk of ER-positive BC (HR for $<7$ drinks per week 1.07, 95\% CI 0.84-1.36; HR for $\geq 7$ drinks per week 1.15, 95\% 0.87-1.51, compared with non-drinkers) or ER-negative BC (HR for $<7$ drinks per week $0.69,95 \%$ CI $0.46-1.04$; HR for $\geq 7$ drinks per week 0.89 , 95\% 0.57-1.39, compared with non-drinkers). While we found that FRP did not modify the association for overall $\mathrm{BC}$ (interaction $p$ value 0.19 ), we did find differences by ER subtype. We observed a negative multiplicative interaction by FRP for higher alcohol intake ( $\geq 7$ drinks/week) compared with non-regular drinkers for ER-positive BC. As illustrated in Fig. 2, women at the 10th (which translates to a 5year BOADICEA of $0.15 \%$ ) percentile of FRP had a $46 \%$ increased risk of ER-positive BC (HR 1.46, 95\% CI 1.071.99), while there was no association for women in the 90th percentile (HR 1.07, 95\% CI 0.80-1.44). We observed similar patterns when modeling alcohol use as a continuous variable (data not shown). These results were consistent for other measures of FRP we examined, including 10-year BOADICEA risk score and lifetime risk to age 80 (results not shown).

We found a significant three-way interaction for FRP, alcohol consumption (non-regular drinkers and regular drinkers), and cigarette smoking (current, former, never smokers) (interaction $p$ value $=0.01$ ). When we stratified models examining smoking and $\mathrm{BC}$ risk by alcohol consumption, we found no overall significant association for current or former smoking by regular and non-regular alcohol drinking (Table 4). We examined whether the association of smoking and BC is modified by FRP within strata of alcohol consumption and observed a statistically significant positive interaction with FRP for 
Table 1 Descriptive characteristics of women in the Breast Cancer Prospective Family Study Cohort (ProF-SC) by smoking status and alcohol consumption

\begin{tabular}{|c|c|c|c|c|c|c|}
\hline & $\begin{array}{l}\text { Non-smoker } \\
(N=10,158)\end{array}$ & $\begin{array}{l}\text { Former smoker } \\
(N=4675)\end{array}$ & $\begin{array}{l}\text { Current smoker } \\
(N=2602)\end{array}$ & $\begin{array}{l}\text { Non-regular drinker } \\
(\mathrm{N}=8817)\end{array}$ & $\begin{array}{l}\text { Regular drinker } \\
(N=8618)\end{array}$ & $\begin{array}{l}\text { Total cohort } \\
(N=17,435)\end{array}$ \\
\hline Age at baseline (mean, SD) & $46.5 \pm 15.6$ & $49.2 \pm 14.2$ & $43.6 \pm 14.0$ & $48.0 \pm 15.7$ & $45.5 \pm 14.3$ & $46.8 \pm 15.1$ \\
\hline Age at breast cancer diagnosis (mean, SD) & $55.9 \pm 12.2$ & $58.2 \pm 12.3$ & $52.9 \pm 11.5$ & $57.0 \pm 12.2$ & $55.5 \pm 12.3$ & $56.2 \pm 12.3$ \\
\hline BOADICEA full lifetime risk score, \% (mean, SD) & $23.8 \pm 17.2$ & $22.7 \pm 15.4$ & $23.3 \pm 16.3$ & $23.6 \pm 17.1$ & $23.2 \pm 16.0$ & $23.4 \pm 16.6$ \\
\hline BOADICEA 1-year risk score, \% (mean, SD) & $0.5 \pm 0.6$ & $0.5 \pm 0.6$ & $0.4 \pm 0.6$ & $0.5 \pm 0.7$ & $0.4 \pm 0.6$ & $0.5 \pm 0.6$ \\
\hline BOADICEA 5-year risk score, \% (mean, SD) & $2.4 \pm 3.1$ & $2.6 \pm 3.1$ & $2.2 \pm 2.8$ & $2.5 \pm 3.2$ & $2.4 \pm 2.9$ & $2.4 \pm 3.0$ \\
\hline Body mass index, $\mathrm{kg} / \mathrm{m}^{2}$ (mean, SD) & $25.8 \pm 5.6$ & $26.3 \pm 5.7$ & $25.3 \pm 5.7$ & $26.5 \pm 5.9$ & $25.2 \pm 5.3$ & $25.8 \pm 5.7$ \\
\hline \multicolumn{7}{|l|}{ Cigarette smoking variables } \\
\hline Age at smoking initiation, years (mean, SD) & NA & $18.7 \pm 5.2$ & $18.1 \pm 5.4$ & $18.9 \pm 6.0$ & $18.3 \pm 4.8$ & $18.5 \pm 5.3$ \\
\hline Smoking duration, years smoked (mean, SD) & NA & $14.5 \pm 11.6$ & $23.9 \pm 13.4$ & $19.0 \pm 13.6$ & $17.0 \pm 12.7$ & $17.7 \pm 13.1$ \\
\hline Smoking intensity, cigarettes/day (mean, SD) & NA & $13.1 \pm 10.8$ & $15.1 \pm 9.3$ & $14.0 \pm 10.6$ & $13.7 \pm 10.1$ & $13.8 \pm 10.3$ \\
\hline \multicolumn{7}{|l|}{ Smoking intensity, cigarettes/day $(n, \%)$} \\
\hline Non-smoker ${ }^{a}$ & $10,158(100.0)$ & NA & NA & $6286(71.3)$ & $3872(44.9)$ & $10,158(58.3)$ \\
\hline 1 to $<5$ cig/day & NA & $992(21.2)$ & $242(9.3)$ & $413(4.7)$ & $821(9.5)$ & $1234(7.1)$ \\
\hline 5 to $<10$ cig/day & NA & $888(19.0)$ & $421(16.2)$ & $440(5.0)$ & $869(10.1)$ & $1309(7.5)$ \\
\hline 10 to $<20$ cig/day & NA & $1321(28.3)$ & $936(36.0)$ & $823(9.3)$ & $1434(16.6)$ & $2257(13.0)$ \\
\hline$\geq 20$ more cig/day & NA & $1434(30.7)$ & $980(37.7)$ & $830(9.4)$ & $1584(18.4)$ & $2414(13.9)$ \\
\hline Missing & 0 & $40(0.9)$ & $23(0.9)$ & $25(0.3)$ & $38(0.4)$ & $63(0.4)$ \\
\hline \multicolumn{7}{|l|}{ Smoking duration, years smoked $(n, \%)$} \\
\hline Non-smoker & $10,158(100.0)$ & NA & NA & $6286(71.3)$ & $3872(44.9)$ & $10,158(58.3)$ \\
\hline$<10$ years & NA & 1900 (40.6) & $388(14.9)$ & $728(8.3)$ & $1560(18.1)$ & $2288(13.1)$ \\
\hline 10 to $<20$ years & NA & $1367(29.2)$ & $582(22.4)$ & $621(7.0)$ & $1328(15.4)$ & 1949 (11.2) \\
\hline 20 to $<30$ years & NA & $701(15.0)$ & $646(24.8)$ & $507(5.8)$ & $840(9.8)$ & $1347(7.7)$ \\
\hline$\geq 30$ years & NA & $622(13.3)$ & $821(31.6)$ & $585(6.6)$ & $858(10.0)$ & $1443(8.3)$ \\
\hline Missing & 0 & $85(1.8)$ & $165(6.3)$ & $90(1.0)$ & $160(1.9)$ & $250(1.4)$ \\
\hline \multicolumn{7}{|l|}{ Alcohol consumption variables } \\
\hline Total drinks per week (mean, SD) & $6.0 \pm 7.0$ & $8.0 \pm 10.1$ & $10.9 \pm 14.0$ & NA & $7.7 \pm 10.0$ & $7.7 \pm 10.0$ \\
\hline Age at drinking initiation (mean, SD) & $25.5 \pm 11.0$ & $23.7 \pm 9.8$ & $22.8 \pm 8.6$ & NA & $24.4 \pm 10.2$ & $24.4 \pm 10.2$ \\
\hline Drinking duration, years (mean, SD) & $15.2 \pm 12.0$ & $18.8 \pm 12.9$ & $16.0 \pm 11.8$ & NA & $16.6 \pm 12.4$ & $16.6 \pm 12.4$ \\
\hline \multicolumn{7}{|l|}{ Categorical drinks per week $(n, \%)$} \\
\hline Non-regular drinker ${ }^{c}$ & $6406(63.1)$ & $1686(36.1)$ & $986(37.9)$ & $8817(100 \%)$ & $261(3.0)^{c}$ & $9078(52.1)$ \\
\hline$<7$ drinks/week & $2420(23.8)$ & $1654(35.4)$ & $763(29.3)$ & NA & $4837(56.1)$ & $4837(27.7)$ \\
\hline$\geq 7$ drinks/week & $1095(10.8)$ & $1158(24.8)$ & $725(27.9)$ & NA & $2978(34.6)$ & $2978(17.1)$ \\
\hline Missing & $237(2.3)$ & $177(3.8)$ & $128(4.9)$ & NA & $542(6.3)$ & $542(3.1)$ \\
\hline \multicolumn{7}{|l|}{$B R C A$ mutation carriers } \\
\hline Non-carrier & $9374(92.3)$ & $4405(94.2)$ & $2430(93.4)$ & $8148(92.4)$ & 8061 (93.5) & $16,209(93.0)$ \\
\hline BRCA1 carrier & $417(4.1)$ & $156(3.3)$ & $105(4.0)$ & $366(4.2)$ & 312 (3.6) & 678 (3.9) \\
\hline BRCA2 carrier & 367 (3.6) & $114(2.4)$ & $67(2.6)$ & $303(3.4)$ & $245(2.8)$ & $548(3.1)$ \\
\hline \multicolumn{7}{|l|}{ Study center } \\
\hline Philadelphia & $444(4.4)$ & $246(5.3)$ & $94(3.6)$ & $420(4.8)$ & $364(4.2)$ & $784(4.5)$ \\
\hline New York & 1211 (11.9) & $616(13.2)$ & $171(6.6)$ & $1074(12.2)$ & $924(10.7)$ & 1998 (11.5) \\
\hline Utah & $666(6.6)$ & $64(1.4)$ & $38(1.5)$ & $617(7.0)$ & $151(1.8)$ & 768 (4.4) \\
\hline Australia & $2147(21.1)$ & 1046 (22.4) & 725 (27.9) & $1864(21.1)$ & 2054 (23.8) & 3918 (22.5) \\
\hline Ontario, Canada & $1241(12.2)$ & 703 (15.0) & $418(16.1)$ & 1160 (13.2) & $1202(14.0)$ & $2362(13.6)$ \\
\hline
\end{tabular}


Table 1 Descriptive characteristics of women in the Breast Cancer Prospective Family Study Cohort (ProF-SC) by smoking status and alcohol consumption (Continued)

\begin{tabular}{|c|c|c|c|c|c|c|}
\hline & $\begin{array}{l}\text { Non-smoker } \\
(N=10,158)\end{array}$ & $\begin{array}{l}\text { Former smoker } \\
(N=4675)\end{array}$ & $\begin{array}{l}\text { Current smoker } \\
(N=2602)\end{array}$ & $\begin{array}{l}\text { Non-regular drinker } \\
(N=8817)\end{array}$ & $\begin{array}{l}\text { Regular drinker } \\
(N=8618)\end{array}$ & $\begin{array}{l}\text { Total cohort } \\
(N=17,435)\end{array}$ \\
\hline Northern California & $1892(18.6)$ & $679(14.5)$ & $380(14.6)$ & $1924(21.8)$ & $1027(11.9)$ & $2951(16.9)$ \\
\hline kConFab & $2557(25.2)$ & $1321(28.3)$ & $776(29.8)$ & 1758 (19.9) & 2896 (33.6) & $4654(26.7)$ \\
\hline \multicolumn{7}{|l|}{ Birth cohort } \\
\hline$<1950$ & $3917(38.6)$ & $2108(45.1)$ & $797(30.6)$ & $3795(43.0)$ & 3027 (35.1) & $6822(39.1)$ \\
\hline 1950-1959 & $2291(22.6)$ & $1151(24.6)$ & $666(25.6)$ & $1975(22.4)$ & $2133(24.8)$ & $4108(23.6)$ \\
\hline 1960-1969 & $2002(19.7)$ & $904(19.3)$ & $638(24.5)$ & $1590(18.0)$ & $1954(22.7)$ & $3544(20.3)$ \\
\hline$\geq 1970$ & $1948(19.2)$ & $512(11.0)$ & $501(19.3)$ & $1457(16.5)$ & $1504(17.5)$ & $2961(17.0)$ \\
\hline \multicolumn{7}{|l|}{ Race } \\
\hline Non-Hispanic White & $7803(76.8)$ & 3998 (85.5) & 2158 (82.9) & $6397(72.6)$ & 7562 (87.8) & $13,959(80.1)$ \\
\hline Non-Hispanic Black & $481(4.7)$ & $170(3.6)$ & $158(6.1)$ & $499(5.7)$ & $310(3.6)$ & $809(4.6)$ \\
\hline Hispanic & $1012(10.0)$ & $287(6.1)$ & $137(5.3)$ & $1057(12.0)$ & $379(4.4)$ & $1436(8.2)$ \\
\hline Asian & $569(5.6)$ & $64(1.4)$ & $32(1.2)$ & $545(6.2)$ & $120(1.4)$ & $665(3.8)$ \\
\hline Other & $244(2.4)$ & $135(2.9)$ & $94(3.6)$ & $271(3.1)$ & $202(2.3)$ & $473(2.7)$ \\
\hline Missing & $49(0.5)$ & $21(0.5)$ & $23(0.9)$ & $48(0.5)$ & $45(0.5)$ & $93(0.5)$ \\
\hline \multicolumn{7}{|l|}{ Education } \\
\hline High school graduate or less & $3161(18.1)$ & $1515(8.7)$ & $1139(6.5)$ & $3391(38.5)$ & $2424(28.1)$ & $5815(33.4)$ \\
\hline Some college/vocational school & $3656(21.0)$ & $1838(10.5)$ & $1106(6.3)$ & $3166(35.9)$ & $3434(39.9)$ & $6600(37.9)$ \\
\hline Bachelor's/graduate degree & $3296(18.9)$ & $1311(7.5)$ & $342(2.0)$ & $2213(25.1)$ & $2736(31.8)$ & $4949(28.4)$ \\
\hline Missing & $45(0.3)$ & $11(0.1)$ & $15(0.1)$ & $47(0.5)$ & $24(0.3)$ & $71(0.4)$ \\
\hline \multicolumn{7}{|c|}{ Parity (number of full-term pregnancies/breastfeeding history) } \\
\hline Nulliparous & $2617(15.0)$ & $871(5.0)$ & $660(3.8)$ & $1857(21.1)$ & $2291(26.6)$ & $4148(23.8)$ \\
\hline Parous 1-2/no breastfeeding & $1037(6.0)$ & $586(3.4)$ & $410(2.4)$ & $1140(12.9)$ & $893(10.4)$ & $2033(11.7)$ \\
\hline Parous 1-2/breastfed & $2626(15.1)$ & $1395(8.0)$ & $667(3.8)$ & $2085(23.7)$ & $2603(30.2)$ & $4688(26.9)$ \\
\hline Parous 3+/no breastfeeding & $758(4.4)$ & $390(2.2)$ & $256(1.5)$ & $854(9.7)$ & $550(6.4)$ & $1404(8.1)$ \\
\hline Parous 3+/breastfed & $3047(17.5)$ & $1387(8.0)$ & $591(3.4)$ & $2820(32.0)$ & $2205(25.6)$ & $5025(28.8)$ \\
\hline Missing & $73(0.4)$ & $46(0.3)$ & $18(0.1)$ & $61(0.7)$ & $76(0.9)$ & $137(0.8)$ \\
\hline \multicolumn{7}{|l|}{ Hormonal birth control us } \\
\hline Never & $2832(16.2)$ & $933(5.4)$ & $469(2.7)$ & $2756(31.3)$ & $1478(17.2)$ & $4234(24.3)$ \\
\hline Former & $5825(33.4)$ & $3194(18.3)$ & $1722(9.9)$ & $5017(56.9)$ & $5724(66.4)$ & $10,741(61.6)$ \\
\hline Current & $1424(8.2)$ & $513(2.9)$ & $393(2.3)$ & $970(11.0)$ & $1360(15.8)$ & $2330(13.4)$ \\
\hline Missing & $77(0.4)$ & $35(0.2)$ & $18(0.1)$ & $74(0.8)$ & $56(0.7)$ & $130(0.8)$ \\
\hline
\end{tabular}

NA not applicable

${ }^{a}$ Smokers are defined as having smoked at least once cigarette per day for 3 months or longer

${ }^{\mathrm{b}}$ Regular drinkers are defined as consuming one alcoholic beverage at least once a week for 6 months or longer

'This includes women who reported being regular drinkers that consumed 0 drinks per week. These women were categorized as non-regular drinkers in the categorical drinks per week variable

current vs never smokers for women who regularly consumed alcohol, but not for non-regular alcohol drinkers. While we found significant multiplicative interaction by FRP ( $p$ value $=0.005)$ for smoking status in women who also consumed alcohol, this was primarily driven by women with very high FRP (Fig. 3). As illustrated in Fig. 3, there was a $30 \%$ increased overall BC risk for women at the 95th percentile of FRP (5-year BOADICEA of $6.55 \%$ ) who reported currently smoking at baseline and were regular drinkers (HR 1.30, 95\% CI 0.99-1.71), and no association for current smokers with the same FRP, but were not regular drinkers (HR 0.94, 95\% CI 0.66-1.35).

The overall findings for smoking and alcohol consumption were similar in sensitivity analyses when limiting to only confirmed invasive BCs and excluding those with diagnosis of (non-breast) cancer prior to baseline (results not shown). The results in Table 2, 3, and 4 by 


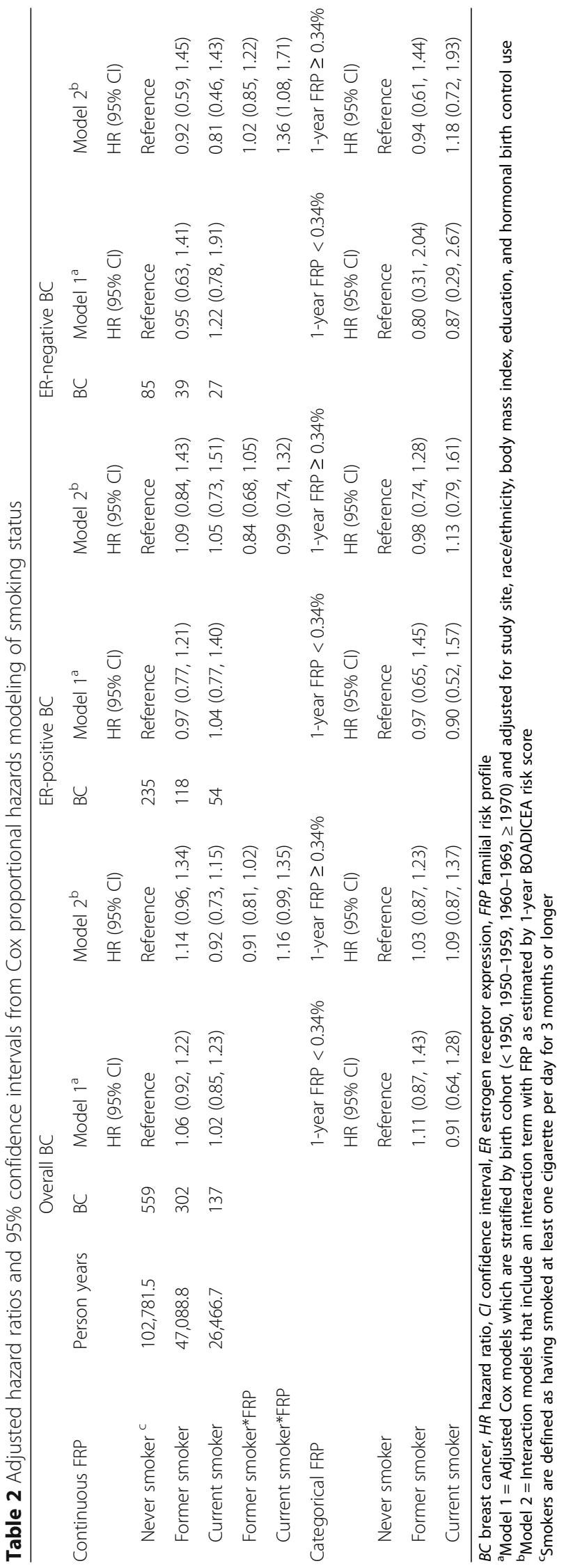


A

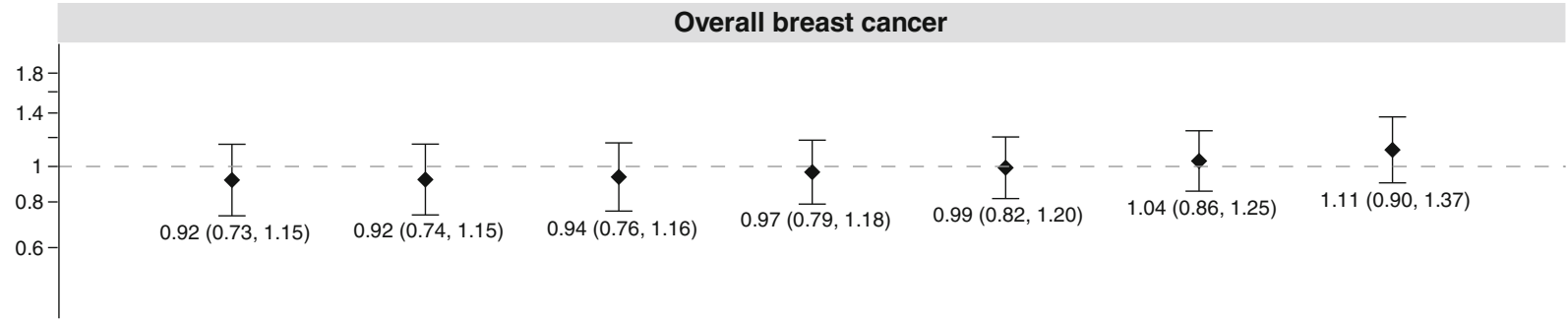

B

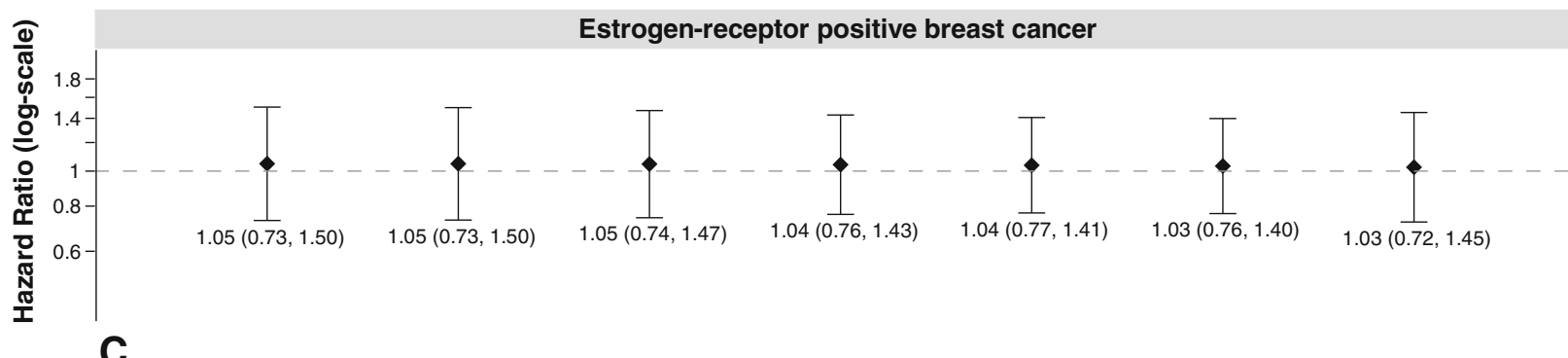

C

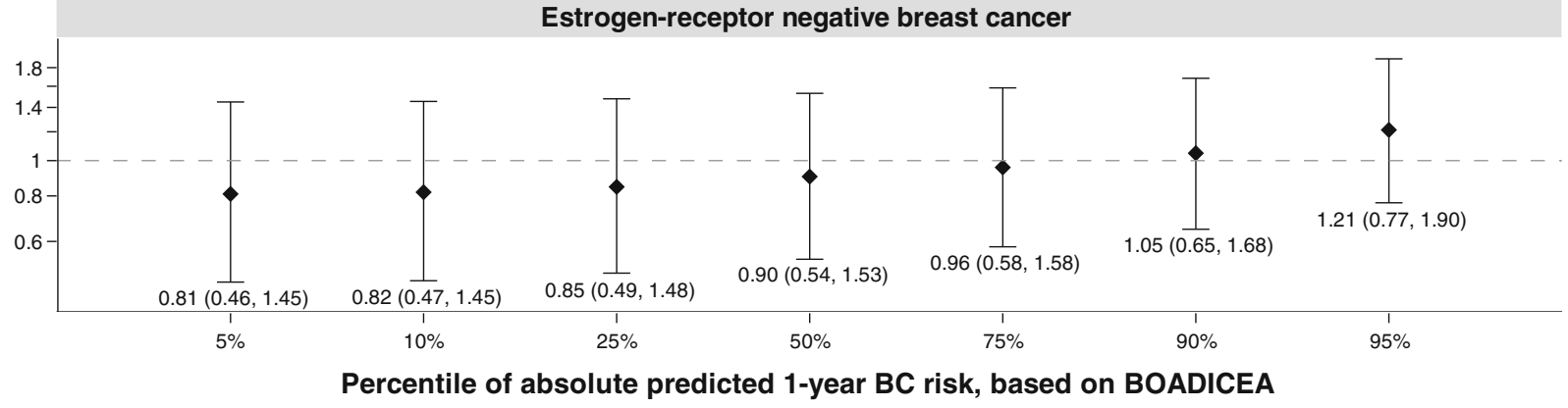

Fig. 1 Associations of current smoking compared to never smoking and breast cancer (BC) risk by percentiles of absolute predicted 1-year BC risk for overall BC, estrogen receptor-positive BC, and estrogen receptor-negative BC. Hazard ratios (HR) reflect associations for current smokers compared to never smokers and breast cancer risk by percentiles of absolute predicted 1-year breast cancer risk, as estimated by BOADICEA for overall breast cancer (panel a), estrogen-receptor positive breast cancer (panel b), and estrogen-receptor negative breast cancer (panel c). HRs are stratified by birth cohort and are adjusted for race/ethnicity, study center, education, oral contraceptive use, and body mass index

ER status were also similar when we used a competing risk framework for ER censoring (results not shown). We did not observe significant associations with $\mathrm{BC}$ risk for smoking intensity, age at smoking initiation, and smoking duration, and there was no evidence of multiplicative interaction between any measure of FRP and any of these smoking and alcohol variables (Additional file 1: Table S1). The overall findings for smoking and alcohol were similar in models excluding $B R C A 1$ and $B R C A 2$ mutation carriers (Additional file 1: Table S2).

\section{Discussion}

We did not observe a statistically significant increase in $\mathrm{BC}$ risk associated with alcohol or tobacco consumption when considering the cohort as a whole, but we did observe some differences by FRP and ER status. Specifically, alcohol intake was associated with increased risk of ER-positive $\mathrm{BC}$ for women at lower predicted absolute risk. For women with a high FRP (above 95th percentile or a 5-year BOADICEA of 6.55\%) who also consumed alcohol, smoking was associated with increased overall $\mathrm{BC}$ risk.

Five previous studies have reported increased BC risk associated with smoking only for women with a family history of $\mathrm{BC}$ or in BRCA1 and BRCA2 mutation carriers [32-36]. This includes a report from the UK Generations study cohort of a $35 \%$ increased BC risk (HR 1.35; 95 CI 1.12-1.62) for women with a family history of $\mathrm{BC}$ who ever smoked, and no increased risk for smokers with no family history of BC [32]. Similarly, the Minnesota breast cancer family study reported ever smoking was associated with a 2.4-fold increased risk for daughters or sisters of women with $\mathrm{BC}$, but not for their nieces or granddaughters [34]. A secondary analysis of high-risk women enrolled in the National Surgical Adjuvant Breast and Bowel Project Breast Cancer Prevention Trial reported that 


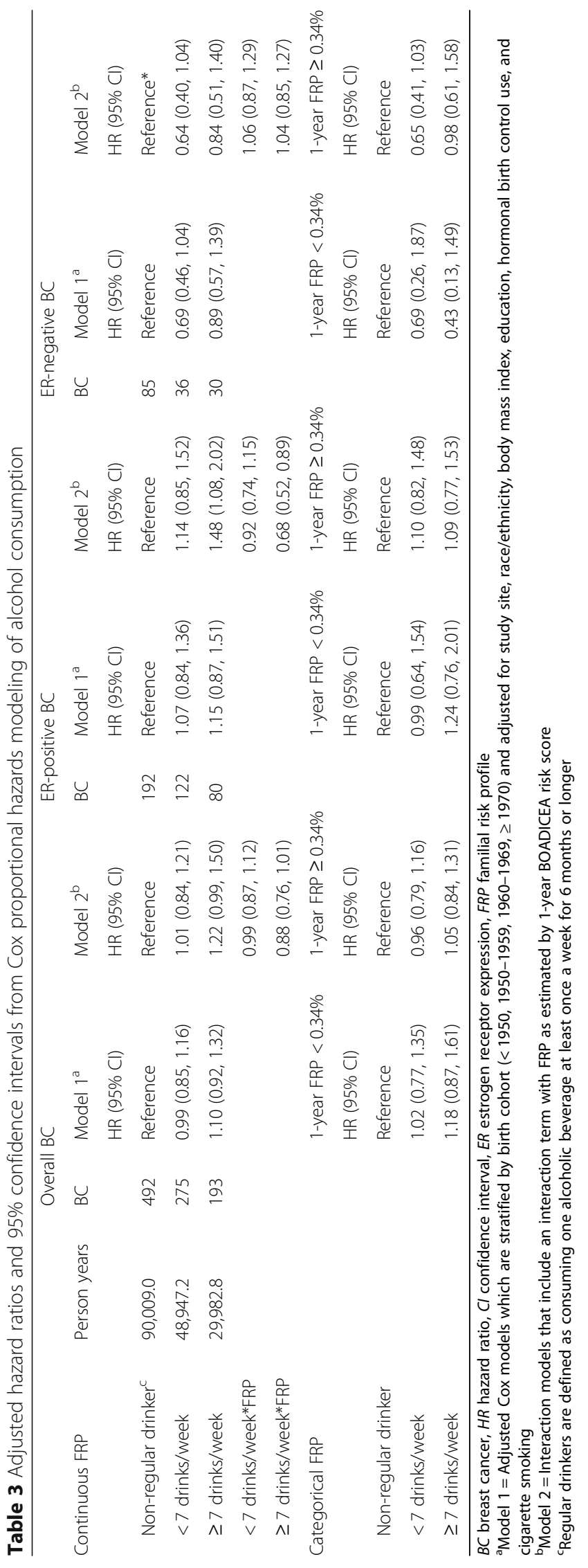


A

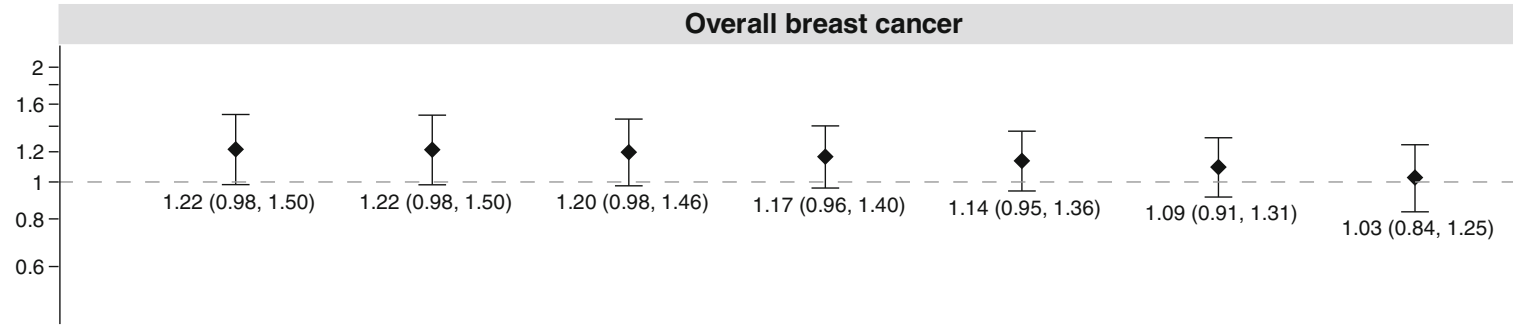

B

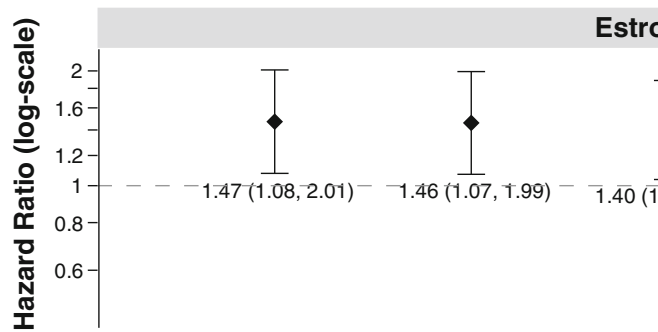

Estrogen-receptor positive breast cancer

C

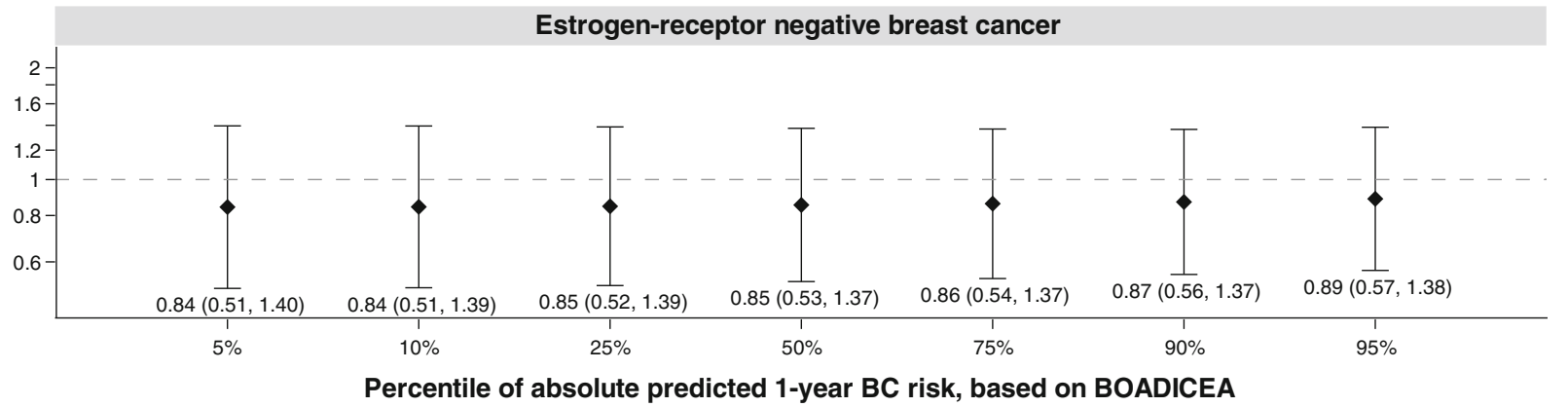

Fig. 2 Associations of consuming $\geq 7$ alcoholic drinks per week (compared to non-regular drinkers) and breast cancer risk by percentiles of absolute predicted 1-year breast cancer risk for overall breast cancer, estrogen receptor-positive breast cancer, and estrogen receptor-negative breast cancer. Hazard ratios (HR) reflect associations for consuming $\geq 7$ alcoholic drinks per week compared to non-drinkers and breast cancer risk by percentiles of absolute predicted 1-year breast cancer risk, as estimated by BOADICEA for overall breast cancer (panel a), estrogen-receptor positive breast cancer (panel b), and estrogen-receptor negative breast cancer (panel c). HRs are stratified by birth cohort and are adjusted for race/ethnicity, study center, education, oral contraceptive use, body mass index, and cigarette smoking

smoking has a greater influence on $\mathrm{BC}$ risk for women with an elevated risk of $\mathrm{BC}$ [35]. Additionally, we previously reported an association between smoking and increased $\mathrm{BC}$ risk for $B R C A 1$ and $B R C A 2$ mutation carriers aged less than 50 years [36]. In the current study, we found a positive interaction between smoking and FRP only for regular alcohol drinkers, pointing to a possible synergistic relationship between FRP, smoking, and alcohol with respect to $\mathrm{BC}$ risk. This is consistent with three previous studies, including a reanalysis of over 22,000 BC cases and a pooled analysis of 14 cohort studies that examined the smoking association by alcohol consumption and found significant associations with measures of smoking only for alcohol drinkers $[8,19,32]$.

We observed evidence for a negative interaction between FRP and alcohol intake in association with ER-positive disease. As previously reported, our family-based cohort is comprised of women across a large range of familial risk [12]. In addition to being enriched with women at higher than average risk, over $30 \%$ of cohort participants are at general population risk (5-year BOADICEA $<1.67 \%$ ), similar to other cohorts unselected for underlying risk. As such, our finding of an increased risk for higher alcohol intake in women at the lower end of the FPR spectrum, which translates into a 5 -year BOADICEA $<1.25 \%$, is consistent with previous reports from average-risk populations of a stronger association between alcohol intake and risk of hormone receptor positive tumors [5].

We were limited to active smoking exposure and did not have information on exposure to environmental tobacco smoke (ETS). Some studies have reported an association with ETS and elevated BC risk, as reviewed elsewhere [37]. Another limitation is that information on smoking and alcohol came from self-report of recalled information, which 


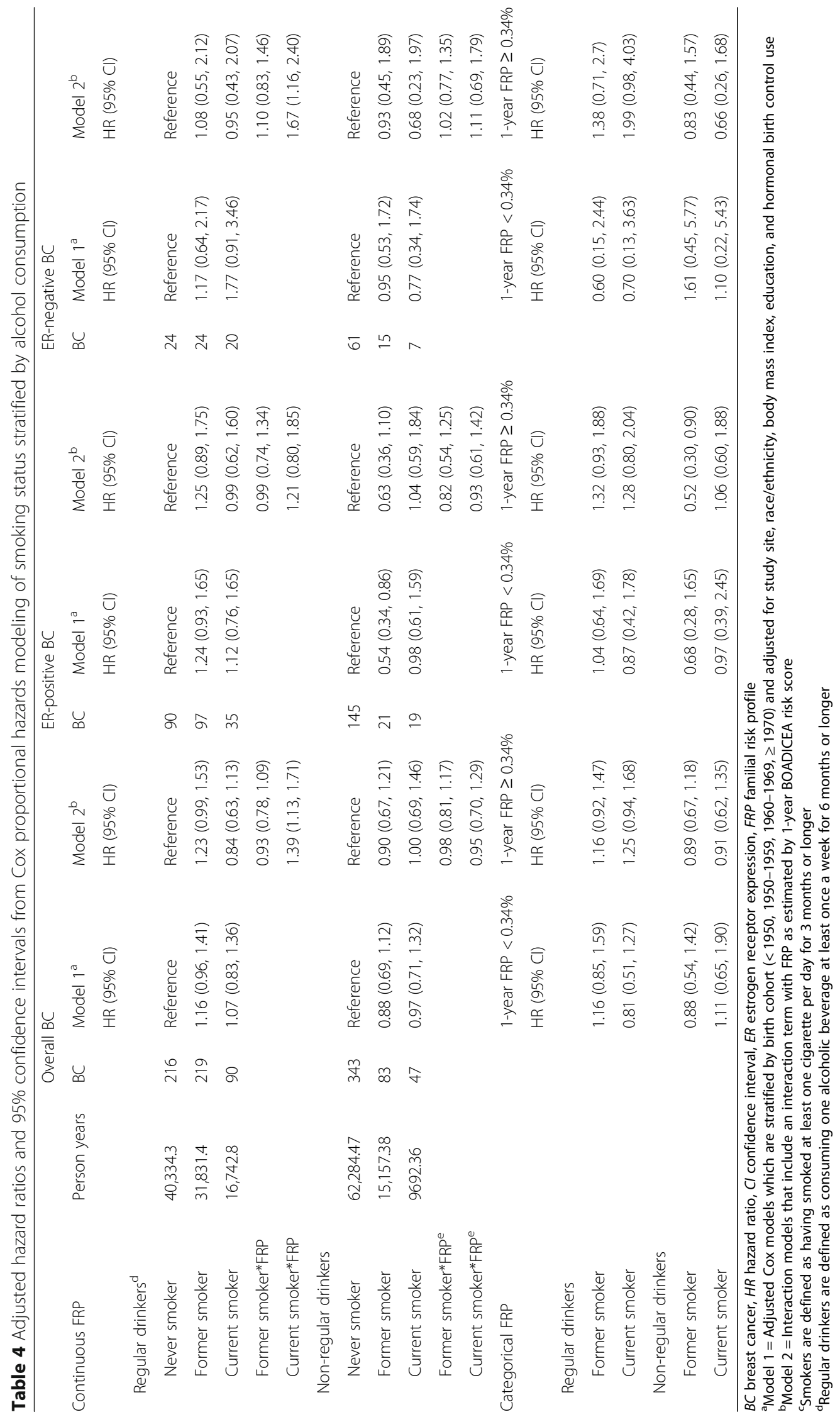


A

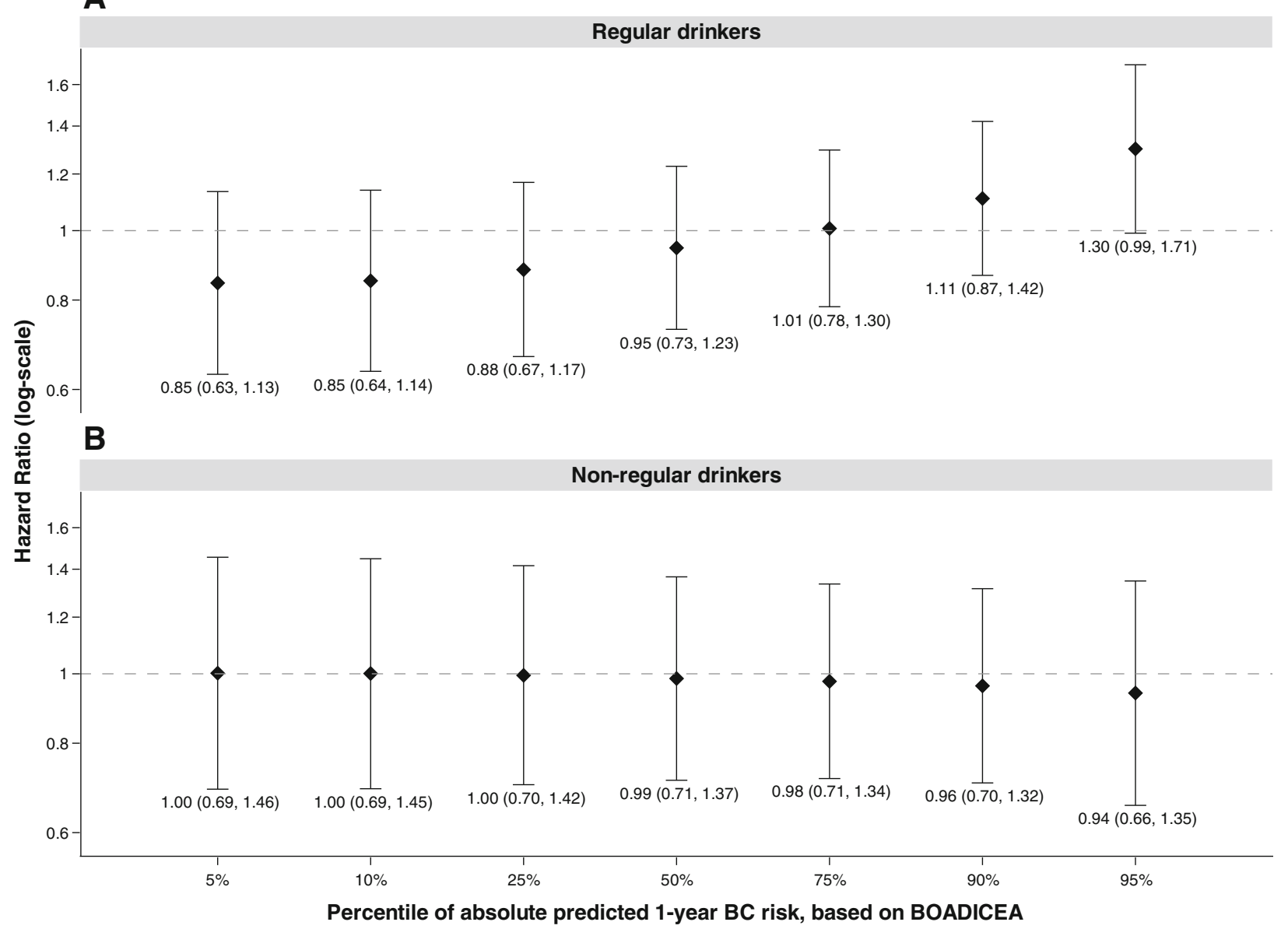

Fig. 3 Associations of current smoking compared to never smoking and breast cancer risk by percentiles of absolute predicted 1-year breast cancer risk stratified by alcohol consumption at baseline. Hazard ratios (HR) reflect associations for current smokers compared to never smokers and breast cancer risk by percentiles of absolute predicted 1-year breast cancer risk, as estimated by BOADICEA, stratified by alcohol consumption status at baseline; regular drinkers are presented in panel $\mathbf{a}$ and non-regular drinkers in panel $\mathbf{b}$. HRs are stratified by birth cohort and are adjusted for race/ethnicity, study center, education, oral contraceptive use, and body mass index

may not be accurate, particularly with respect to amount, frequency, and duration of alcohol intake. However, because the present study was prospective, any measurement error would be non-differential. We also did not have information on binge drinking and could not assess this association with $\mathrm{BC}$ risk. Additionally, the prevalence of reported alcohol consumption in our population was low, so we had limited power to fully assess interaction with FRP at different levels of alcohol consumption, particularly for heavier drinkers and by BC subtype. Similarly, for cigarette smoking, our study was limited by a small number of cases who smoked to fully assess interaction with FRP, particularly by BC subtype.

Our study is strengthened by the comprehensive definition of family history that incorporates pedigree information and age at diagnosis of the relatives, extending beyond the conventional binary variable to cover the entire familial risk profile. The heterogeneity of the cohort with respect to family history allowed us to evaluate women across the full spectrum of risk and, in particular, women at high familial risk.

\section{Conclusion}

Findings from this large prospective cohort including high-risk women indicate that there is an elevated risk of ER-positive BC associated with alcohol consumption for women at average population risk (5-year BOADICEA < $1.25 \%)$. Additionally, while smoking is not strongly associated with $\mathrm{BC}$, and this association is not modified by underlying FRP, there is an increased overall $\mathrm{BC}$ risk for women at very high familial risk (BOADICEA > 6.55\%) who also regularly consumed alcohol. These findings can have implications in terms of absolute risk reduction, as alcohol and smoking are modifiable risk factors and present risk reduction opportunities for women across the spectrum of familial risk. 


\section{Supplementary information}

Supplementary information accompanies this paper at https://doi.org/10. 1186/s13058-019-1213-1

Additional file 1: Table S1. Adjusted hazard ratios and 95\% confidence intervals from Cox proportional hazards modeling of smoking and alcohol variables. Table S2. Adjusted hazard ratios and 95\% confidence intervals from Cox proportional hazards modeling of smoking and alcohol variables, excluding BRCA1 and BRCA2 mutation carriers.

\section{Abbreviations}

BC: Breast cancer; BCFR: Breast Cancer Family Registry; BOADICEA: Breast Ovarian Analysis of Disease Incidence and Carrier Estimation Algorithm; Cl: Confidence interval; ER: Estrogen receptor; FRP: Familial risk profile; HR: Hazard ratio; kConFab: Kathleen Cuningham Foundation Consortium for research into Familial Breast cancer; ProF-SC: Prospective Family Study Cohort

\section{Acknowledgements}

We thank Heather Thorne, Eveline Niedermayr, Lucy Stanhope, Sarah O'Connor, Sandra Picken, all the BCFR and kConFab research nurses and staff, the heads and staff of the Family Cancer Clinics, and the many families who contribute to the BCFR and kConFab for their contributions to this resource.

\section{Authors' contributions}

JLH and MBT conceived the parent study, obtained funding, collected data, analyzed data, interpreted the findings and oversaw the writing of the manuscript. ILA, SSB, MBD, EMJ, KAP conceived the study, obtained funding, collected data, interpreted the findings, and contributed to writing the manuscript. YL helped analyze the data and calculated the predicted absolute risk scores and interpreted the findings. RJM, GSD, RDK, JAK, JMG, MCS, RLM, WKC, GGG, SAM, MLF interpreted the findings and contributed to writing the manuscript. PCW, GG, SN and the kConFab Investigators coordinated the data collection, interpreted the findings, and contributed to writing the manuscript. All authors read and approved the final manuscript.

\section{Funding}

This work was supported by the National Institute of Health USA (grant number 1RO1CA159868). The ABCFR was supported in Australia by the National Health and Medical Research Council, the New South Wales Cancer Council, the Victorian Health Promotion Foundation, the Victorian Breast Cancer Research Consortium, Cancer Australia, and the National Breast Cancer Foundation. The six sites of the Breast Cancer Family Registry (BCFR) were supported by grant UM1 CA164920 from the USA National Cancer Institute. The content of this manuscript does not necessarily reflect the views or policies of the National Cancer Institute or any of the collaborating centers in the BCFR, nor does mention of trade names, commercial products, or organizations imply endorsement by the US Government or the BCFR. This work was supported by grants to kConFab and the kConFab Follow-Up Study from the Cancer Australia (grant number 809195); the Australian National Breast Cancer Foundation (grant number IF 17 kConFab); the National Health and Medical Research Council (grant numbers 454508, 288704, 145684); the National Institute of Health USA (grant number 1RO1CA159868); the Queensland Cancer Fund; the Cancer Councils of New South Wales, Victoria, Tasmania, and South Australia; and the Cancer Foundation of Western Australia (grant numbers not applicable). KAP is a National Breast Cancer Foundation (Australia) Practitioner Fellow (grant number PRAC-17-004). RDK is supported by the National Institutes of Health $(\mathrm{NIH})$, National Cancer Institute, Cancer Epidemiology Training Grant (grant number T32-CA009529). NZ is supported by the NIH National Center for Advancing Translational Sciences (NCATS), TL1 Training Program (grant number TL1TR001875)

\section{Availability of data and materials}

The datasets analyzed during the current study are available from the corresponding authors on reasonable request.

\section{Ethics approval and consent to participate}

All participants in the BCFR and kConFab provided written informed consent before participation. Human research ethics committees at the participating institutions granted ethics approval for the six sites of the BCFR and for kConFab:

- Northern California - Cancer Prevention Institute of California, Institutional Review Board (2001-033) and Stanford University School of Medicine, Institutional Review Board (45842)

- New York-Columbia University Medical Center, Institutional Review Board (AAA7794)

- Philadelphia-Fox Chase Cancer Center, Institutional Review Board (95-009)

- Utah-Huntsman Cancer Institute, University of Utah, Institutional Review Board (00004965)

- Ontario-Mount Sinai Hospital Research Ethics Board (\#02-0076-U) and University Health Network Research Ethics Board (\#96-U107-CE)

- Australia-University of Melbourne, Human Ethics Sub-Committee (1441420.1)

- kConFab-Peter MacCallum Cancer Centre, the Peter Mac Ethics Committee (97/27)

\section{Consent for publication}

Not applicable

\section{Competing interests}

The authors declare that they have no competing interests.

\section{Author details}

${ }^{1}$ Department of Epidemiology, Mailman School of Public Health, Columbia University, 722 W. 168th Street, Room 1611, New York, NY 10032, USA. ${ }^{2}$ Lunenfeld-Tanenbaum Research Institute, Sinai Health System, Toronto, Ontario, Canada. ${ }^{3}$ Dalla Lana School of Public Health, University of Toronto, Toronto, Ontario, Canada. ${ }^{4}$ Herbert Irving Comprehensive Cancer Center, Columbia University Irving Medical Center, New York, NY, USA. ${ }^{5}$ Centre for Epidemiology and Biostatistics, The University of Melbourne, Parkville, Victoria, Australia. ${ }^{6}$ Department of Medical Oncology, Peter MacCallum Cancer Centre, Melbourne, Victoria, Australia. ${ }^{7}$ Sir Peter MacCallum Department of Oncology, The University of Melbourne, Melbourne, Victoria, Australia. ${ }^{8}$ Department of Clinical Genetics, Fox Chase Cancer Center, Philadelphia, PA, USA. ${ }^{9}$ Cancer Epidemiology Division, Cancer Council Victoria, Melbourne, Victoria, Australia. ${ }^{10}$ Precision Medicine, School of Clinical Sciences at Monash Health, Monash University, Clayton, Victoria, Australia. ${ }^{11}$ Department of Clinical Pathology, The University of Melbourne, Parkville, Victoria, Australia. ${ }^{12}$ Departments of Pediatrics and Medicine, Columbia University, New York, NY, USA. ${ }^{13}$ Department of Medicine, St Vincent's Hospital, The University of Melbourne, Parkville, Victoria, Australia. ${ }^{14}$ Department of Medical Oncology, St Vincent's Hospital, Fitzroy, Victoria, Australia. ${ }^{15}$ Prince of Wales Clinical School, University of New South Wales, Sydney, New South Wales, Australia. ${ }^{16}$ Department of Medical Oncology, Prince of Wales Hospital, Randwick, New South Wales, Australia. ${ }^{17}$ The Research Department, The Peter MacCallum Cancer Centre, Melbourne, Victoria, Australia. ${ }^{18}$ Departments of Molecular Genetics and Laboratory Medicine and Pathobiology, University of Toronto, Toronto, Ontario, Canada.

${ }^{19}$ Department of Medicine and Huntsman Cancer Institute, University of Utah Health Sciences Center, Salt Lake City, UT, USA. ${ }^{20}$ Department of Medicine and Stanford Cancer Institute, Stanford University School of Medicine, Stanford, CA, USA

Received: 13 June 2019 Accepted: 15 October 2019 Published online: 28 November 2019

\section{References}

1. Shield KD, Soerjomataram I, Rehm J. Alcohol use and breast cancer: a critical review. Alcohol Clin Exp Res. 2016;40(6):1166-81

2. Hamajima N, Hirose K, Tajima K, Rohan T, Calle EE, Heath CW Jr, Coates RJ, Liff JM, Talamini R, Chantarakul N, et al. Alcohol, tobacco and breast cancer--collaborative reanalysis of individual data from 53 epidemiological studies, including 58,515 women with breast cancer and 95,067 women without the disease. Br J Cancer. 2002;87(11):1234-45.

3. McDonald JA, Goyal A, Terry MB. Alcohol intake and breast cancer risk: weighing the overall evidence. Curr Breast Cancer Rep. 2013;5(3):208-221.

4. Smith-Warner SA, Spiegelman D, Yaun SS, van den Brandt PA, Folsom AR, Goldbohm RA, Graham S, Holmberg L, Howe GR, Marshall JR, et al. Alcohol 
and breast cancer in women: a pooled analysis of cohort studies. JAMA. 1998;279(7):535-40.

5. Liu Y, Nguyen N, Colditz GA. Links between alcohol consumption and breast cancer: a look at the evidence. Women's Health. 2015;11(1):65-77.

6. Jung $S$, Wang M, Anderson K, Baglietto L, Bergkvist L, Bernstein L, van den Brandt PA, Brinton L, Buring JE, Eliassen AH, et al. Alcohol consumption and breast cancer risk by estrogen receptor status: in a pooled analysis of 20 studies. Int J Epidemiol. 2016;45(3):916-28.

7. Reynolds P. Smoking and breast cancer. J Mammary Gland Biol Neoplasia. 2013;18(1):15-23.

8. Gaudet MM, Carter BD, Brinton LA, Falk RT, Gram IT, Luo J, Milne RL, Nyante $S J$, Weiderpass E, Beane Freeman $L E$, et al. Pooled analysis of active cigarette smoking and invasive breast cancer risk in 14 cohort studies. Int J Epidemiol. 2017;46(3):881-93.

9. Macacu A, Autier P, Boniol M, Boyle P. Active and passive smoking and risk of breast cancer: a meta-analysis. Breast Cancer Res Treat. 2015;154(2):21324.

10. Friebel TM, Domchek SM, Rebbeck TR. Modifiers of cancer risk in BRCA1 and BRCA2 mutation carriers: systematic review and meta-analysis. J Natl Cancer Inst. 2014;106(6):dju091.

11. Ko KP, Kim SJ, Huzarski T, Gronwald J, Lubinski J, Lynch HT, Armel S, Park SK, Karlan B, Singer CF, et al. The association between smoking and cancer incidence in BRCA1 and BRCA2 mutation carriers. Int J Cancer. 2018;142(11): 2263-72.

12. Terry MB, Phillips K-A, Daly MB, John EM, Andrulis IL, Buys SS, Goldgar DE, Knight JA, Whittemore AS, Chung WK, et al. Cohort profile: the breast cancer prospective family study cohort (ProF-SC). Int J Epidemiol. 2015;45(3): 683-92.

13. Hopper JL, Dite GS, Maclnnis RJ, Liao Y, Zeinomar N, Knight JA, Southey MC, Milne RL, Chung WK, Giles GG, et al. Age-specific breast cancer risk by body mass index and familial risk: prospective family study cohort (ProF-SC). Breast Cancer Res. 2018;20(1):132.

14. Kehm RD, Hopper JL, John EM, Phillips KA, Maclnnis RJ, Dite GS, Milne RL, Liao Y, Zeinomar N, Knight JA, et al. Regular use of aspirin and other nonsteroidal anti-inflammatory drugs and breast cancer risk for women at familial or genetic risk: a cohort study. Breast Cancer Res. 2019;21(1):52.

15. Zeinomar N, Phillips KA, Daly MB, Milne RL, Dite GS, Maclnnis RJ, Liao Y, Kehm RD, Knight JA, Southey MC, et al. Benign breast disease increases breast cancer risk independent of underlying familial risk profile: findings from a Prospective Family Study Cohort. Int J Cancer. 2019;145(2):370-379.

16. Quante AS, Herz J, Whittemore AS, Fischer C, Strauch K, Terry MB. Assessing absolute changes in breast cancer risk due to modifiable risk factors. Breast Cancer Res Treat. 2015;152(1):193-7.

17. Cui Y, Miller A, Rohan T. Cigarette smoking and breast cancer risk: update of a prospective cohort study. Breast Cancer Res Treat. 2006;100(3):293-9.

18. Gaudet MM, Gapstur SM, Sun J, Diver WR, Hannan LM, Thun MJ. Active smoking and breast cancer risk: original cohort data and meta-analysis. J Natl Cancer Inst. 2013;105(8):515-25.

19. Gram IT, Braaten T, Terry PD, Sasco AJ, Adami H-O, Lund E, Weiderpass E. Breast cancer risk among women who start smoking as teenagers. Cancer Epidemiol Biomark Prev. 2005;14(1):61-6.

20. Nyante SJ, Gierach GL, Dallal CM, Freedman ND, Park Y, Danforth KN, Hollenbeck AR, Brinton LA. Cigarette smoking and postmenopausal breast cancer risk in a prospective cohort. Br J Cancer. 2014;110(9):2339-47.

21. Reynolds $P$, Hurley $S$, Goldberg DE, Anton-Culver H, Bernstein L, Deapen $D$, Horn-Ross PL, Peel D, Pinder R, Ross RK, et al. Active smoking, household passive smoking, and breast cancer: evidence from the California teachers study. J Natl Cancer Inst. 2004;96(1):29-37.

22. Schatzkin A, Jones DY, Hoover RN, Taylor PR, Brinton LA, Ziegler RG, Harvey EB, Carter CL, Licitra LM, Dufour MC, et al. Alcohol consumption and breast cancer in the epidemiologic follow-up study of the first National Health and Nutrition Examination Survey. N Engl J Med. 1987;316(19):1169-73.

23. John EM, Hopper JL, Beck JC, Knight JA, Neuhausen SL, Senie RT, Ziogas A, Andrulis IL, Anton-Culver H, Boyd N, et al. The Breast Cancer Family Registry: an infrastructure for cooperative multinational, interdisciplinary and translational studies of the genetic epidemiology of breast cancer. Breast Cancer Res. 2004;6(4):R375.

24. Osborne RHR. KConFab: a research resource of Australasian breast cancer families. Kathleen Cuningham Foundation Consortium for Research into Familial Breast Cancer. Med J Aust. 2000;172(9):463-4.
25. Phillips K-A. Predictors of participation in clinical and psychosocial follow-up of the kConFab breast cancer family cohort. Familial Cancer. 2005:4(2):10513.

26. Mann GJ, Thorne H, Balleine RL, Butow PN, Clarke CL, Edkins E, Evans GM, Fereday S, Haan E, Gattas M, et al. Analysis of cancer risk and BRCA1 and BRCA2 mutation prevalence in the kConFab familial breast cancer resource. Breast Cancer Res. 2006;8(1):R12.

27. Neuhausen SL, Ozcelik H, Southey MC, John EM, Godwin AK, Chung W, Iriondo-Perez J, Miron A, Santella RM, Whittemore A, et al. BRCA1 and BRCA2 mutation carriers in the Breast Cancer Family Registry: an open resource for collaborative research. Breast Cancer Res Treat. 2009;116(2):37986.

28. Antoniou AC, Cunningham AP, Peto J, Evans DG, Lalloo F, Narod SA, Risch HA, Eyfjord JE, Hopper JL, Southey MC, et al. The BOADICEA model of genetic susceptibility to breast and ovarian cancers: updates and extensions. Br J Cancer. 2008;98(8):1457-66.

29. Antoniou AC, Pharoah PP, Smith P, Easton DF. The BOADICEA model of genetic susceptibility to breast and ovarian cancer. Br J Cancer. 2004;91(8) 1580-90.

30. Tehranifar P, Wu HC, Shriver T, Cloud AJ, Terry MB. Validation of family cancer history data in high-risk families: the influence of cancer site, ethnicity, kinship degree, and multiple family reporters. Am J Epidemiol. 2015;181(3):204-12.

31. Terry MB, Liao Y, Whittemore AS, Leoce N, Buchsbaum R, Zeinomar N, Dite GS, Chung WK, Knight JA, Southey MC, et al. 10-year performance of four models of breast cancer risk: a validation study. Lancet Oncol. 2019;20(4): 504-17.

32. Jones ME, Schoemaker MJ, Wright LB, Ashworth A, Swerdlow AJ. Smoking and risk of breast cancer in the Generations Study cohort. Breast Cancer Res. 2017;19(1):118.

33. Suzuki T, Matsuo K, Wakai K, Hiraki A, Hirose K, Sato S, Ueda R, Tajima K. Effect of familial history and smoking on common cancer risks in Japan. Cancer. 2007;109(10):2116-23.

34. Couch FJ, Cerhan JR, Vierkant RA, Grabrick DM, Therneau TM, Pankratz VS, Hartmann LC, Olson JE, Vachon CM, Sellers TA. Cigarette smoking increases risk for breast cancer in high-risk breast cancer families. Cancer Epidemiol Biomarkers Prev. 2001;10(4):327-32.

35. Land SR, Liu Q, Wickerham DL, Costantino JP, Ganz PA. Cigarette smoking, physical activity, and alcohol consumption as predictors of cancer incidence among women at high risk of breast cancer in the NSABP P-1 trial. Cancer Epidemiol Biomarkers Prev. 2014;23(5):823-32.

36. Breast Cancer Family Registry, Kathleen Cuningham Consortium for Research into Familial Breast Cancer (Australasia) \& Ontario Cancer Genetics Network (Canada). Smoking and risk of breast cancer in carriers of mutations in BRCA1 or BRCA2 aged less than 50 years. Breast Cancer Res Treat. 2008. 109(1):67-75.

37. Lee PN, Hamling JS. Environmental tobacco smoke exposure and risk of breast cancer in nonsmoking women. An updated review and metaanalysis. Inhal Toxicol. 2016;28(10):431-54.

\section{Publisher's Note}

Springer Nature remains neutral with regard to jurisdictional claims in published maps and institutional affiliations.

Ready to submit your research? Choose BMC and benefit from:

- fast, convenient online submission

- thorough peer review by experienced researchers in your field

- rapid publication on acceptance

- support for research data, including large and complex data types

- gold Open Access which fosters wider collaboration and increased citations

- maximum visibility for your research: over $100 \mathrm{M}$ website views per year

At BMC, research is always in progress.

Learn more biomedcentral.com/submissions 